\title{
Prevention and Treatment of Cancer: Hypes and Hopes 6th International Translational Cancer Research Conference
}

\author{
PRABHUDAS PATEL ${ }^{1}$, HEMANGINI VORA ${ }^{1}$, BHARAT B. AGGARWAL ${ }^{2}$, \\ VARSHA GANDHI $^{2}$, KAPIL MEHTA $^{2}$ and SEN PATHAK ${ }^{2}$ \\ ${ }^{I}$ Department of Cancer Biology, The Gujarat Cancer \& Research Institute, \\ New Civil Hospital Campus, Asarwa, Ahmedabad, India; \\ ${ }^{2}$ The University of Texas, M.D. Anderson Cancer Center, Houston, TX, U.S.A.
}

\begin{abstract}
Cancer is primarily an "old-age" disease that has an "age-old" history. The overall incidence of cancer is much higher in Western countries, but is rapidly growing in Eastern countries perhaps due to change in life-style. Almost three million studies published to date indicate that cancer is a hyperproliferative disorder that arises from dysregulation of multiple cell signaling pathways. The cancer genome landscape indicates that approximately 140 genes and 12 cell signaling pathways drive almost all cancers. "Targeted therapy," a buzz word in cancer treatment for the past two decades, has provided antibodies, as well as small-molecule inhibitors. These therapies have been successful only in few instances. However, in most cases, minor increase in overall survival has been reported at the cost of huge expense. An alternative strategy is to prevent cancer or to diagnose and treat the disease at an early stage to gain survival benefits. Such interventions are also cost-effective. To address some of these issues, the 6th International Translational Cancer Research Conference was held during February 4-7th, 2016, in Ahmedabad, Gujarat, India; the homeland of Mahatma Gandhi. This conference was focused on utilizing multidisciplinary approaches for prevention and early treatment that would likely simultaneously or sequentially target many key pathways. Several distinguished speakers were invited from around the world. This article highlights primary features of this conference.
\end{abstract}

International Society for Translational Cancer Research (ISTCR) was formed in 2005 with the aim to bring both

Correspondence to: Prabhudas Patel, Ph.D., Professor \& Head Department of Cancer Biology, The Gujarat Cancer \& Research Institute, New Civil Hospital Campus, Asarwa, Ahmedabad-380016, India. Tel: +91 9825489376, e-mail: prabhudas_p@hotmail.com

Key Words: Translational cancer research, prevention, therapeutics, conference. clinicians and scientists together to strengthen the fight against cancer. Since then, ISTCR has organized five highly successful conferences at various places, including Thiruvananthapuram, Bhubaneswar, Udaipur, Mumbai and Delhi in India. The major focus of this conference was to discuss recent developments in translational cancer research to treat and prevent cancer. The 6th TCR conference was a collaboration between Gujarat Cancer Research Institute (GCRI), Ahmedabad, India and M.D. Anderson Cancer Center (MDACC), Houston, TX, USA. In addition to four days conference, two pre-conference events were also organized.

\section{Pre-Conference events}

The pre-conference events included: (i) Cancer Walk followed by Lok Darbar (Public Forum) Cancer Awareness Program for General Public and (ii) Cancer Awareness Program for College Students.

Cancer Walk was organized by the GCRI, Ahmedabad, from Shivranjani Cross Road Satellite to Sadvichar Parivar, Ramdevnagar, in which around 150 delegates participated. The goal was to spread awareness among the general public about various aspects of cancer. The walk was flagged off by Dr. Bharat Aggarwal, USA, at 5:00 p.m. on February 02, 2016. All participants walked with various banners (both in local and English language) highlighting to quit tobacco habits, such as cigarette smoking, gutkha chewing, alcohol consumption, along with importance of dietary habits and measures to be taken for early screening and treatment of cancer. They also recited slogans for anticancer campaign that created an enthusiastic atmosphere and great interest for general public.

The rally reached the venue of Cancer Lok Darbar, "Sadvichar Parivar Kendra", Ramdevnagar. Dr. Hemangini Vora spearheaded this event. There was an interactive session with the Media representatives with the intent to spread the Cancer awareness amongst general public by means of newspapers and television. Around 500 delegates participated 
in this event. The program began with a prayer by Ms. Anal Mehta, followed by welcome address by Dr. R.K. Vyas, the Director of GCRI. Dr. Pankaj M. Shah, former Director, introduced the dignitaries and spoke on the importance of Cancer Lok Darbar. Shri Asitbhai Vora, dynamic Chairman of Gujarat Subordinate Services Selection Board and Former Mayor of Ahmedabad Municipal Corporation were the Chief Guests for the event. He addressed the gathering with inspirational and educative speeches.

Most time was devoted to the question-answer session. The inquisitive public asked various questions pertaining to cancer etiology regarding tobacco habit, lifestyle factors, cancer as hereditary disease, signs and symptoms, cancer as infectious disease, types of treatment and their side-effects, disease outcome due to delay of treatment, cost-effective treatment, usefulness of stem cell, bone marrow transplantation, the need for routine cancer health checkups, etc. The questions were addressed by the leading cancer clinicians Drs. R.K. Vyas, Pankaj M. Shah, Devendra D. Patel, Kirti M. Patel, Mukund Mehta, Kiran C. Kothari, Geeta Joshi and cancer researchers Drs. Prabhudas S. Patel, Bharat Aggarwal, Varsha Gandhi, Kapil Mehta and SenPathak. The program was concluded at 9:30 p.m. with concluding remarks by Dr. Prabhudas Patel.

\section{Cancer Awareness Program for Students}

"Cancer Awareness Program" for College Students was organized at Thakorbhai Desai Hall, Law garden, Ahmedabad, on February 03, 2016 from 9:30 a.m. to 1:00 p.m. The program was coordinated by Dr. Rakesh M. Rawal. Around 500 college students and faculties of all disciplines from colleges across the city actively participated in this event. The program started with the prayer and lamp lightning ceremony. The Chief Guest was Dr. M. N. Patel, Vice Chancellor, Gujarat University and Guest of Honor was Shri Kshitish Madanmohan, Secretary, Gujarat Cancer Society (GCS). Dr. Geeta Joshi, Deputy Director, GCRI, delivered the welcome speech to the students. Dr. Shilin N. Shukla, former Director, GCRI, introduced the dignitaries and explained the detailed theme of the program. Other dignitaries on the dais were Drs. R.K Vyas, Bharat Aggarwal, Prabhudas Patel, Varsha Gandhi, Kapil Mehta and Sen Pathak. Further, the dignitaries addressed the gathering. An elocution competition was organized on Cancer prevention theme and Exhibition was also there on various aspects of cancer screening, early signs, prevention, diagnosis and treatment. Fourteen students participated in the competition. A skit on Cancer Awareness was performed by a group of students from the H.K. Arts College. The prizes were awarded to winners of the competition. The first, second and third place winners were: Utpal Solanki, Depander Tivari, Shikha Chauhan and Chetan Prajapati (a tie), respectively.
The skit performed by Nilesh \& group was awarded special prize. The program was concluded with the vote of thanks by Dr. Varsha Gandhi, MDACC.

\section{Inaugural Function and Keynote Address}

The Conference was inaugurated on February 04, 2016, i.e. on "World Cancer Day". The grand inaugural program of the "6th International Translational Cancer Research Conference", with the theme "Prevention and Treatment of Cancer: Hypes and Hopes" was held at the Hyatt Regency hotel, Ahmedabad. More than 400 delegates from 10 countries and 82 institutions participating in the 4-day conference; invitees and media representatives attended the inaugural function. The chief guest was Dr. Pankaj Shah, Former Director, GCRI, and Vice President of GCS, while the Guest of Honor was Mr. S.N. Tyagi, Mission Director, Gujarat State Biotechnology Mission. Chief Guest and Guest of Honor were felicitated. Dr. R.K. Vyas Director, GCRI, welcomed all the dignitaries and participants. Dr. Sen Pathak read the message received by the conference from the Prime Minister of India, Mr. Narendra Modiji. Dr. Mehta read the message received from Mrs. Anandiben Patel, Chief Minister of Gujarat State.

Dr. Prabhudas Patel, Chair local organizing Committee, introduced the theme of the conference. Dr. Bharat Aggrawal, Founder Member, ISTCR, gave an inspirational talk on mission and vision of the society. In inaugural speech, Shri S.N. Tyagi, Director, Gujarat State Biotechnology Mission (GSBTM), emphasized to initiate joint research projects between Pharma and academic institutions, which will be supported by Gujarat State and GSBTM. He also recommended multi-institutional collaborative projects to enhance and propel academic research. He further mentioned that these initiatives should be undertaken by today's youngsters under the guidance of experts.

Dr. Shah's presentation focused on targeted therapy and small molecules that are invented due to translational cancer research approach. He discussed about novel research activities in the field of Translational Cancer Research and the future directives to be taken by the experts. He also presented an overview of various steps taken by different organizations and government policies like "Ma Yojana" to help the general public for cancer treatment.

The inaugural function ended with vote of thanks by Dr. Geeta Joshi, Deputy Director, GCRI. After a short tea break, Drs. Mitali Mukerji and Bhavana Prasher, New Delhi, set the stage for scientific session with keynote lectures related to Ayurgenomics.

On second day, i.e. February 05, 2016, of the conference, the first Scientific Session "Cancer prevention/Cancer Metastasis" began at 8:30 a.m. and was chaired by Dr. Kapil Mehta, USA and Dr. Devendra D. Patel, Ahmedabad. After a brief introduction on the topic by Dr. Kapil Mehta, 


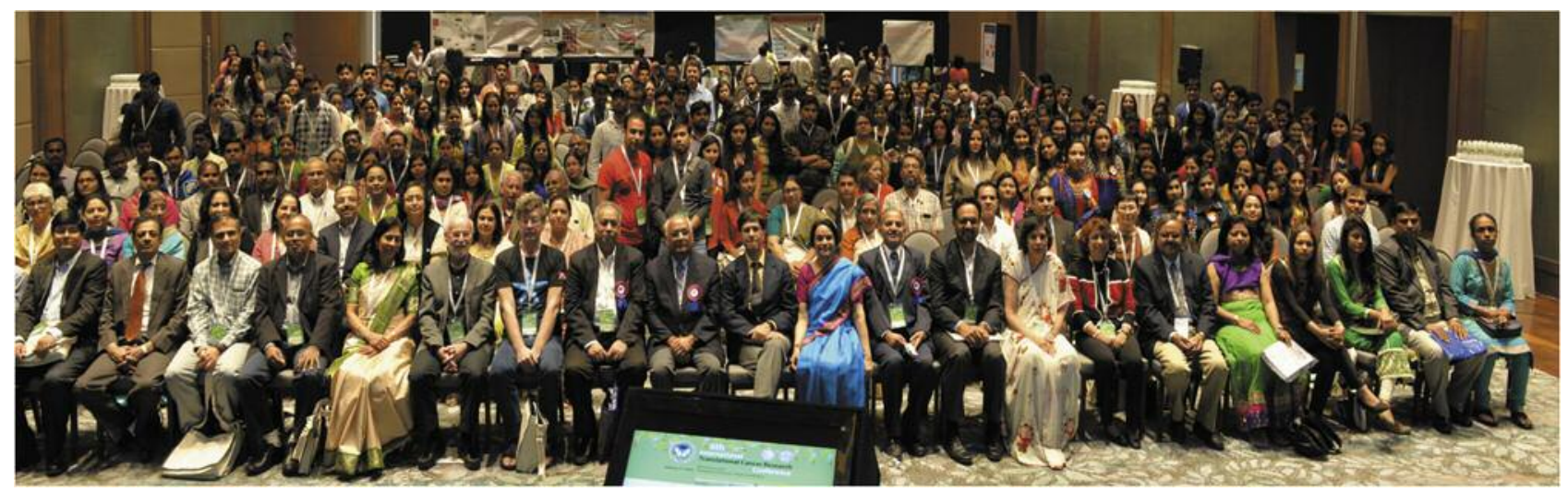

Figure 1. Group photograph of attendees of the 6th Translational Cancer Research Conference in Ahmedabad, Gujarat, India.

MDACC, USA, Dr. Sopit Wongkham, Dr. Faye Johnson, Dr. Rakesh Singh and Dr. G.K Rath shared their knowledge on multi-molecular approaches for discovery of alternative targets, PI3K/mTOR pathway inhibitors, chemokine signaling in cancer metastasis and the concepts and strategies for cancer prevention in India.

The second session on "Cancer Epigenetics" was chaired by Dr. Sen Pathak, USA and Dr. Rakesh Vyas, GCRI. Dr. Shiv Grewal, Dr. Devarajan Karunagaran and Dr. Bhavana Dave enlightened delegates with their in-depth knowledge on the topics of non-coding RNA and diseases, miRNA-145 modulating Wnt signaling and highlights of translational medicine in non-Hodgkin lymphoma. Simultaneously, during the lunch session, 60 posters displayed from different Institutes, covering different aspects of new developments in the field of cancer research by Students and Research Scholars, were viewed and judged. There were fruitful discussions/ suggestions from the judges, which certainly helped the students for their future research work.

The third post-lunch session was on "Cancer Drug Development". The session was introduced by Dr. Sarat Dalai, Ahmedabad and Dr. Ravi Malhotra, Noida. Invited faculties Dr. Saraswati Sukumar, Dr. Kumkum Khanna, Dr. Sunil Kaul and Dr. B.C. Das covered different aspects of drug development targeting molecules like ER-responsive genes, DNA damage response pathway, Fos related antigen Fra-1 and anticancer activity of Ashwagandha leaves.

The fourth session was on "Cancer Prevention/Cancer Metastasis" chaired by Dr. Prabhudas S. Patel and Dr. Purvish Parikh. The speakers covered diverse topics like therapeutic efficacy of nutritional herbs on models for molecular subtypes of clinical breast cancer, inhibition of metastasis by PEITC, factors involved in gallstone formation in gallbladder cancer, disordered transcriptional repressor domain of MBD1 interaction effects with binding partners.
The fifth session was on "Cancer Proteomics" chaired by Dr. Rakesh Singh and Dr. Amit Verma. Dr. Ritu Aggarwal, Dr. Mark McDowall, Dr. Savita Yadav and Dr. A.J. Vanisree discussed different aspects of proteomics involving proteomic profiling of retinoblastoma, mass spectrometry imaging in cancer, salivary proteomics for cervical cancer and role of growth regulating protein and receptor in enhancement of sensitization to chemotherapeutic agents. Thereafter, all the conference delegates, along with invited faculties, proceeded for cultural programme: Ras Garba at Sabarmati River Front, with delicious Kathyavadi food.

On February 06, 2016, the first session was on "Cancer Microenvironment" chaired by Dr. N.K. Jain and Dr. Perunuma Sudhakaran. In this session, Dr. Jacques Pouyssegur, Dr. Sarita Gupta, Dr. Alpana Sharma and Dr. Subhash Chandra Gupta shared their knowledge on bioenergentics in hypoxic tumors, role of stem cells in prostate cancer, bone marrow microenvironment in multiple myeloma progression and role of acidic microenvironment in breast cancer.

Next session was ISTCR-ISO Panel discussion on: "Translational Cancer Research from clinic to laboratory". The leading topics related to cancer in India, i.e. lung cancer, breast cancer and oral cancer, were discussed with the expertise knowledge of different panelists. The first panel discussion was on Lung Cancer. Dr. Chirag Desai gave an overview of recent development in lung cancer. The session was moderated by Dr. Pankaj M. Shah. Different panelists, including Dr. Varsha Gandhi, Dr. Chirag Desai, Dr. Asha Anand, Dr. Rakesh Rawal and Dr. Priti Trivedi, actively discussed important aspects and addressed different questions related to lung cancer. It also highlighted clinical significance EGFR-modified targeted therapies. Thereafter, the panel discussion was on breast cancer. Dr. Saraswati Sukumar, USA, gave an overview of recent developments with an enhanced knowledge covering all aspects of early 
detection, diagnosis and treatment. Dr. Harit Chaturvedi, moderator, actively carried forward the panel discussion with active participation of the panelists Dr. Saraswati Sukumar, Dr. Kapil Mehta, Dr. Kiran Kothari, Dr. Hemangini Vora, Dr. Dhaval Jetly, Dr. Sanjeev Misra and Dr. Sonia Parikh. They discussed various points covering dietary fats and breast cancer, prevention strategies, screening tools, mutational analysis, blood testing and exploring the role of miRNA and different target molecules like Her2 and Myc. The session concluded with panel discussion on Oral Cancer. Dr. Faye Johnson gave an overview of recent developments in oral cancer and alarmed on the sharp increase in incidence rate of oral cancer among younger population. The session was moderated by Dr. Pankaj Chaturvedi. He effectively mentioned to all the panelists and conference delegates to fight against oral cancer by a campaign to stop all the tobacco habits, a major culprit of oral cancer. The panelists were Dr. Shiv Grewal, Dr. Faye Johnson, Dr. Ravi Mehrotra, Dr. Prabhudas S. Patel and Dr. Pooja Nandwani Patel. They all discussed importance of immunotherapy for advanced disease, genomics, cetuximab with radiotherapy in HPV+ cases, role of HPV, salivary diagnostics and importance of glycosylation in monitoring oral carcinogenesis process. This was followed by lunch and Poster viewing session. There were around 50 posters presented by students. The delegates and judges had ample interaction with student participants, which encouraged the students to think out of the box for future innovative research.

Afternoon session on "Cancer Personalized Medicine" was chaired by Dr. Varsha Gandhi and Dr. Pankaj Chaturvedi. Dr. Varsha Gandhi gave an overview of the session, which was discussed in-depth by various speakers: Dr. RenuWadhwa, Dr. Neeta Singh, Dr. Kaiser Jamil who, in their talks, covered wide topics like Mortalin in human carcinogenesis process, HPV and cervical cancer.

Next, there was a parallel session on "Cancer Immunology-I and II", which were chaired by Dr. G. Nareshkumar and Dr. Harit Chaturvedi, as well as Dr. Hemangini H. Vora and Dr. Oommen V., respectively. Eminent speakers, including Dr. Shubhada Chiplunkar, Dr. Divyesh Mehta, Dr. Rajeev Tyagi, Dr. Periaswamy Selvaraj, Dr. Shashikala Inamdar and Dr. Subrajit Biswas, discussed in-depth knowledge on gamma delta $\mathrm{T}$ cells in gallbladder cancer, immunotherapy of breast cancer, long-lived immunoregulatory human dendritic cells induced by intracellular pathogen, novel personalized immunotherapy for cancer, lectins recognizing tumor-specific antigens and alterations of apoptotic sensitivity of hepatic stellate cells with sorafenib resistance.

After the Cancer Immunology sessions, there were 3 parallel sessions. Young scientist oral presentations award session by $\mathrm{Ph} . \mathrm{D}$ research scholars and two oral presentation sessions by faculties. The young scientists explored enormous potential of their research work followed by brainstorming discussion with the students. The presentations were also evaluated. As there was good number of participation by young scientists, the session was continued to the next day. After the stimulating scientific interactive day, there was the refreshing KARAOKE musical evening, at Sabarmati riverfront. All the conference delegates enjoyed the music, singing and dancing along with dinner.

The young scientist award session and oral presentation sessions were continued from 8:00 a.m. to 9:40 a.m. on February 07, 2016. The next session was on "Cancer Prevention: The Holistic Appraoch-I" chaired by Dr. Rakesh M. Rawal and Dr. Girija Kuttan. Dr. Krishna Misra, Dr. Prashanta Banerji and Dr. Pratip Banerji explored their knowledge on various topics like enhancement of therapeutic potential and bioavailability of curcumin and ultra diluted medicines for treatment of lung cancer.

Further, there were parallel sessions on Cancer Prevention: The "Holistic Approach-II" chaired by Dr. Sunil kumar, Ahmedabad, Dr. Parag Mehta, USA and "Cancer Drug Development-II" chaired by Dr. Shilin N. Shukla, Ahmedabad, Dr. Ramadas Kuttan, Thrissur. Various speakers, Dr. Kiran Kalia, Dr. Jayashree Joshi, Dr. Donald J.L. Jones, Dr. Sunil Ganatra, Dr. Cheppail Ramachandran, Dr. Siefgried Knasmueller, Dr. Katharina Pachmann, Dr. Alpana Saxena, Dr. Suparna Sengupta, Dr. MeenaJhanwar-Uniyal, Dr. Priya Srinivas, Dr. Mukul Jain, Dr. Tejal Mehta and Dr. Subhash Chauhan, delivered talks on tobacco and oral cancer, target preventive therapy with turmeric oil extract, searching of novel circulating chemopreventive biomarkers through dietary rice brand, anticancer inhibition in silico and in vitro studies, mango ginger extract: a promising neutraceutical anticancer agent, impact of coffee consumption on human cancer and effectiveness of curcuma preparations on tumor stem cells, circulating prognostic markers in lung cancer, reversible p53 independent action on Ras-Raf-ERK-DR5 axis makes diaminothiazoles highly promising for cancer therapy, glioblastoma and its stem cells, novel clues for targeting therapy in breast cancer, preclinical characterization of ZYTP1 in management of solid tumors, formulation and development to lutein nanocrystals and development of new therapeutic approaches for pancreatic cancer.

The session was followed by Valedictory Function conducted by Dr. Nandita Ghosh. Dr. Prabhudas Patel, Chair Organizing committee, wholeheartedly appreciated all members of organizing committee for their enormous contribution for the success of the conference. This was followed by vote of thanks by Dr. Prabhudas S. Patel. Further, Dr. Kapil Mehta awarded the winners for their outstanding performance in poster presentation, young scientist award session. The winners for Outstanding Poster Awards Gaurav Chauhan from The M.S. University of Baroda, Shruti Patel from GCRI, Anil Krupp from Waters 
Corporation, Padmavathi G. from IIT, Guwahati, Ankit Borisa from Institute of Pharmacy, Nirma University, Anal Mehta from GCRI, Kinjal Gajjar from GCRI, Kinjal Bhadresha R. from Illa Devi Hospital, Dhara Bhimani from GCRI, Akil Mansuri from NIPER, Ahmedabad, Riya Mehta/Anita Makwana from MSc. Student, Gujarat University, Aishwariya, Nair/Sana Munshi from MSc Student, Gujarat University, Thakur Monika from MSc Student, Gujarat University. The winners for Young Scientist Award session were1st Prize Swarnendra Singh from National Institute of Immunology, 2nd Prize Shanaya Patel from GCRI, 2nd Prize Dhavan Sharma from Nirma University, Ahmedabad, and 3rd Prize Anindita Deka from IIT, Guwahati, and 3rd Prize Nupur Patel from GCRI.

Dr. Kapil Mehta announced that the next Translational Cancer Research conference will be held at Indian Institute of Technology, Madrasunder, the leadership of Dr. D. Karunagaran during January 2018. The 6th TCR conference ended with a joyful atmosphere with a wish to meet again during the next conference.

\section{Acknowledgements}

We sincerely thank the following organizations for their colossal support. M.D. Anderson Cancer Center, Houston, Texas, USA. Indian Council for Medical Research, India. Gujarat State Biotechnology Mission, Gujarat, India. Gujarat Council on Science and Technology, Gujarat, India.

We also appreciate generous support by: Sabinsa Corporation NJ, Roche Products Pvt. Ltd India, Positive Bioscience India, Imperial Life Sciences (P) Limited India, Premas Life Science India and various other Companies.
Both International and local organizing committees are greatly thankful to the core committee members, including Dr. Nandita Ghosh, Dr. Rakesh Rawal, Dr. Trupti Trivedi, Dr. Jayendra Patel, Dr. PinaTrivedi, for their wholehearted contributions for the success of the events.

\section{References}

1 World Cancer Report-2014. http://apps.who.int/bookorders/ anglais/detart 1 .jsp?

2 India Today - High tide of cancer. http://www.readwhere.com/ publication/1154/India-Today/vol/221966.

3 Mehta K, Gandhi V and Aggarwal BB: All pathways to cancer apoptosis meeting in Thiruvananthapuram (India): Meeting Report. Cell Death Differ 13: 2163-2164, 2006.

4 Gandhi V, Mehta K, Pathak S, Ravindran B, Mishra S and Aggarwal BB: City of Temples Discusses Signaling Templates in Cancer Cells: Meeting Report. Anticancer Res 30: 2477-2480, 2010.

5 Gandhi V, Mehta K, Pathak S and Aggarwal BB: Leaders in Translational Cancer Research meet in Udaipur, a Historical Town in India: An International Symposium on Translational Cancer Research: Cancer Prevention. Anticancer Res 33: 17771782, 2013.

6 Mehta K, Gandhi V, Pathak S, Aggarwal BB and Grover RK: Multitargeted approach to cancer treatment: an international translational cancer research symposium. <http:// www.ncbi.nlm.nih.gov /pubmed/25368293>Anticancer Res 34(11): 6791-6795, 2014. PMID:25368293

$7 \mathrm{http}: / /$ sandesh.
Received June 25, 2016

Revised July 12, 2016

Accepted July 13, 2016 